\title{
FILOSOFIA, AÇÃO E FILOSOFIA POLÍTICA
}

\author{
Renato Janine Ribeiro
}

Devo começar dizendo que, se o convite de Renato Lessa para participar desta mesa me agradou muitíssimo, por outro lado me sinto numa situação estranha, meio gauche, já que sou aqui o único a não militar nas áreas que formam as ciências sociais, concentrando-me na Filosofia Política.

E por isso mesmo precisarei principiar pela diferença da Filosofia Política em relação à Filosofia. A Filosofia Política não é simplesmente a Filosofia aplicada à questão da política. Não cabe, pois, investigar sua differentia specifica perante um gênero mais amplo. Talvez o que ela tenha em comum com a Filosofia em geral é uma forma de abordar as coisas, que contrasta radicalmente com a das ciências. Em Filosofia não se pode dizer que um sistema de pensamento seja refutado, superado ou substituído. Evidentemente, isso ocorrerá se o sistema for mal elaborado. Mas, daquelas dezenas de grandes ou melhores sistemas filosóficos de que dispomos, ao longo de 2.500 anos, não cabe dizer que nenhum tenha sido refutado, superado ou substituído. Cada um desses sistemas — se partirmos de suas regras próprias, dos postulados e da sintaxe que estabeleceram para a dedução e a derivação de suas proposições - tem uma coerência que não pode ser desmentida. Evidentemente, isso implica que haja sintaxes diferentes desses sistemas, e que eles partam de princípios distintos. Mas, se eu tomar, por exemplo, Descartes, se, como ele, partir da dúvida metódica, que culmina em duvidar de tudo que há no mundo, e assim seguir o seu itinerário, não caberá refutá-lo. Posso, está claro, discordar. Posso, por exemplo, dizer que a opção cartesiana depõe excessiva ênfase no indivíduo, no eu que examina a si próprio. Posso até articular isso com determinado momento histórico, de avanço do individualismo, do capitalismo - o que, aliás, exigiria uma série de matizes, para não cairmos num reducionismo simplista. Posso, sem incorrer no simplismo que denuncio, ligar a Filosofia cartesiana à dominação sobre o mundo e à construção da tecnologia, uma vez que Descartes - como seu contemporâneo Francis Bacon - pretende que a ciência faça de nós senhores e donos do mundo. Todas estas críticas posso emitir. Posso também dizer, a partir de Hegel, que o método não é algo que se possa cindir da própria 
construção do sistema filosófico: Descartes assim terá sido, talvez, um tanto infeliz ao considerar que o método se separava do andamento do sistema filosófico. Mas nada disso significa uma refutação do sistema, porque este subsiste: tem seus pontos de partida, tem sua sintaxe, ou suas regras de derivação ou colocação em seqüência das proposições.

Já isto distingue a Filosofia e as ciências. De um modo ou outro, elas têm alguma crença, ainda que mitigada, em alguma forma de progresso. Pode ser o caso das ciências ditas exatas, que vão deletando os "erros do passado", e das quais a imagem que se tem é mais do seu último resultado, quase podemos dizer, on line. Pois a Filosofia, seguramente, não é on line! As ciências humanas, é óbvio, não são presa de uma visão tão simples de progresso, mas também lidam com uma falseabilidade de suas proposições (como mostra Popper), que enseja um certo avanço no trato de seus objetos. Na Filosofia, essa idéia de avanço não existe, e para dizermos tudo, nem um referente tangível, mensurável, legitimador do discurso. $\mathrm{Na}$ verdade, esse é o ponto de partida da Filosofia. Não sei se isso faz nossos interlocutores rirem, mas certamente lhes causa muita estranheza: às vezes faz que nos considerem ridículos. Aliás, é engraçado que aqui eu até esteja sobraçando uma pasta da SBPC, que afinal de contas é uma sociedade para o progresso da ciência, e de cuja diretoria faço parte, quando sou de uma área que não é ciência nem crê, ou pode crer, no progresso.

Em suma, há na Filosofia novos sistemas que surgem, mas esses sistemas não implicam que um sistema anterior tenha sido refutado. Então, há uma espécie de validade, digamos, epistemológica, ou simplesmente simultânea, de todos os sistemas. Isso traz certas conseqüências, e alguns problemas sérios. Por exemplo, para nós a história de nossa disciplina se reveste de uma importância que para nenhuma ciência terá a respectiva história. Considero importante, nas ciências humanas, estudar-se a própria história. Mas na Filosofia isso é decisivo. O risco é óbvio: transformar-nos em sacerdotes de tal ou qual filósofo. E passarmos a vida cultuando tal autor. Aliás, Paulo Arantes, tratando justamente da história do departamento em que ambos trabalhamos, efetua uma crítica veemente à tradição da Filosofia da USP, por ter aberto mão do propósito de filosofar em favor de fazer, essencialmente, história da Filosofia. Este é nosso risco, por assim dizer, nosso acidente de trabalho. Mas, salvo esse excesso indesejável, há validade na freqüentação dos clássicos, por continuarem contribuindo para a compreensão das coisas do mundo.

Expliquemo-nos: dizia que os objetos, ou o mundo em geral, não têm para nós, em Filosofia, o papel legitimadorque possuem para as ciências em geral, inclusive as humanas. Elas se legitimam por referência a algo exterior, que explicam, em que interferem. Em nosso caso, como partimos do pensamento, são as compreensões, as fundações do mundo mesmo que entram em jogo. Daí que o fato de Descartes duvidar do mundo seja emblemático: a questão é como, com nosso instrumental por excelência, o pensamento, concebemos — no sentido forte do verbo o mundo.

Talvez isso permita entender a aproximação da Filosofia, no caso, não tanto das ciências humanas e sociais, mas das humanidades, das letras e das artes. É óbvio que não há sentido em dizer que Dom Quixote ou que outro clássico tenha sido refutado. Sem dúvida essas obras podem deixar de existir, de ser lidas, até desaparecer — isso acontece — mas refutação não ocorre. Diria mais: os clássicos valem por sua freqüentação recíproca, pela comunicação que instauram numa figura pelo menos triangular, que compreende, sempre, no mínimo duas obras e um leitor, porque quando lemos um estamos sempre pressupondo todas as demais leituras que já fizemos ou faremos, ou que outros fizeram e farão, e que, todas e todos, estão presentes virtualmente em nossa freqüentação dos clássicos. Clássico é aquele livro do qual a leitura é exemplar. Não defino o clássico tanto pela escrita modelar, mas sobretudo pela leitura exemplar. Clássico é aquele que lemos ou, supomos, devemos ler.

Ora, talvez isto se aplique à Filosofia. Permito-me dar um exemplo: tenho ficado impressionado pelos discursos que hoje ocorrem sobre o que é chamado a cidadania democrática. Penso no discurso dos direitos humanos e no 
discurso sobre a reforma do Estado. São discursos respeitáveis. Os planos de direitos humanos, nacional e estaduais, são coisa importantíssima e digna. Mas o que me parece curioso é que, nesse discurso, enfatiza-se o direito a ter um Estado eficiente e honesto. Ora, essa temática é mais da república que da democracia. Quando, assim, o ministro Bresser Pereira denomina o direito a um Estado honesto, que preste serviços corretamente, como constituindo uma "cidadania democrática", sua meta essencial é que o detentor de um mandato público não se aproprie dele para uso próprio, não caia no vício do patrimonialismo: ora, essa é a idéia romana da res publica, exigindo de todos que coloquem o bem comum à frente do bem pessoal. É Bruto, o cônsul dos inícios da república, mandando executar os próprios filhos quando traem a pátria, dispondo-se a promover o retorno dos Tarqüínios. É Múcio Sévola queimando a própria mão porque ela não soube matar o inimigo de Roma. São inúmeras histórias de sacrifício pela pátria. Ou, ainda, é Montesquieu analisando, em meados do século XVIII, a república em O espírito das leis, e resumindoa na idéia de que o princípio desse regime é a virtude, que prefiro traduzir como abnegação, como o que antepõe o bem comum ao privado.

Mas esse não é o tema da democracia. Se remontamos aos gregos, é ela o poder dos polloi, os vários, os muitos, que são os pobres. Isso é um tema constante do seu pensamento político: se os muitos, os pobres, tomarem o poder, há enorme risco de que confisquem o bem dos ricos e de que adotem sobre esses uma tirania que não é melhor que a de um sobre muitos.

Esses temas servem para mostrar como certos referenciais, que podem ser Aristóteles, Montesquieu etc., ajudam a localizar um discurso político e permitem dizer, por exemplo, que o discurso político hoje proferido pelo Poder Executivo federal soa mais republicano que democrático - o que trabalhei em outro lugar —; e mais republicano, na medida em que retoma a questão do bem comum, que exigiria de cada um colocar seus interesses pessoais atrás dos coletivos. Esse discurso implica também considerar toda a demanda de um grupo, toda a demanda de uma coletividade como estando imbuída de propósitos egoístas; e este é o ponto crucial desta leitura. O discurso ora dominante é a denúncia do corporativismo, a transformação de cada um dos esboços de demos que ocorrem na sociedade em algo que se desqualifica, porque se afirma que estaria movido por intenções egoístas e, portanto, contrárias ao bem comum, ao espírito republicano.

Esse é um exemplo de como pode servir a Filosofia Política para pensar questões do nosso tempo. O que a freqüentação dos clássicos traz? Qual o presente que o clássico tem? Montesquieu, não por acaso, é dito por muitos - estou pensando na tese de doutorado de Durkheim - um dos fundadores ou dos precursores das ciências sociais; o mesmo, aliás, o próprio Durkheim e também Lévi-Strauss dizem de Rousseau. Mas podemos também ativar Aristóteles e outros autores.

Contudo, se assim procurei indicar o papel que a Filosofia pode ter na leitura da política, ainda não tratei da diferença entre a Filosofia e a Filosofia Política, pela qual esta última não é uma mera província da Filosofia, não é apenas a aplicação da Filosofia ao campo específico do poder. $\mathrm{Na}$ verdade, se, por exemplo, examinamos os currículos e cursos de Filosofia, notamos um viés dominante da Filosofia entre nós, que prioriza a questão do ser e a do conhecimento. Ora, a Filosofia Política reside numa outra questão, também clássica, mas que nos últimos tempos terá perdido na profissão filosófica um tanto de seu destaque, que é a da ação. Esta abrange a Ética e a Filosofia Política, embora com diferenças, já que a Ética geralmente trata da ação do homem individual e a Filosofia Política, do coletivo. O que ora me interessa é distinguir a Filosofia da ação e a teoria do conhecimento. As questões da ação sofrem, nos currículos de Filosofia, uma certa discriminação, raramente sendo tratadas em história da Filosofia, onde se privilegiam as discussões sobre o conhecimento ou o ser. Se essa discriminação contra a ação é infeliz, mostra-se, porém, significativa do fato de que a Filosofia tem um lado seu que é refúgio. Isto exige um parêntese. 
Partamos de uma expressão que já foi corrente: levar as coisas com filosofia. Isso sempre significou a capacidade de aguentar os trancos do mundo, as adversidades. Um dos papéis da Filosofia é a capacidade, desde os tempos antigos, de encarar as dificuldades e os tempos adversos. Certamente a maior parte das pessoas o ignora, mas o livro mais lido na Idade Média, ou seja, durante mil anos — isso não é pouco tempo numa lista de best sellers! —, o livro mais lido do ano 400 ao ano 1.400, depois da Bíblia, foi $A$ consolação da Filosofia, de Boécio. Esse pensador foi executado, a mando de um rei bárbaro, no século $\mathrm{V}$ da era cristã, e ao que parece escreveu na prisão esse livro, que é paradigmático da Filosofia como consolação. Toda uma tradição o continua. Aquilo que Hamlet evoca em seu belíssimo monólogo "Ser ou não ser" — suportar as dilações da lei, o favoritismo e a injustiça do poder, as frustrações do amor —; ou a obra que Thomas Morus escreve enquanto aguarda a morte na Torre de Londres, seu Diálogo da consolação contra a tribulação; ou ainda os Devaneios do caminhante solitário, de Rousseau, tudo isso indica uma capacidade da Filosofia para o refúgio, de nos armar contra as agruras insuportáveis e invencíveis. Temos, nesta relação, dois homens, Boécio e Thomas Morus, que vão ser injustamente executados, e outro, Rousseau, que pode ter tido mania de perseguição, mas que efetivamente foi marginalizado. Nessas condições, vão eles construir uma forma de pensar o mundo, de pensar a si, de pensar uma saída do insuportável, do terminal. Não é pouca coisa. Mas isso implica a opção por um tipo de Filosofia. Veremos qual.

Há um velho recorte, que nos vem pelo menos dos romanos, que é o do otium versus o negotium, que não têm as acepções hoje usuais (e até vale a pena indagar por que mudaram tanto de sentido, com o ócio indicando hoje um lazer banalizado, e o negócio aquele conjunto de atividades que envolvem o ganhar dinheiro). O otium é, mais ou menos, a vita contemplativa. Não é simplesmente o lazer ou o estar à margem do mundo do trabalho; é, estando à margem do mundo do trabalho manual, poder com isso freqüentar o saber, os grandes valores, o conhecimento. Já negotium vem da negação do otium, antepondo-lhe a partícula negativa nec. É misturar-se nos negócios públicos, aceitar o burburinho do mundo, interessar-se pela coisa pública, pela coisa política. Não é demais dizer que a maior parte dos filósofos opta pela vida contemplativa. Será essa, aliás, a grande crítica que Hannah Arendt formula à Filosofia Política. Ela entende que a Filosofia Política é a tentativa de subordinar o conhecimento da coisa pública à Filosofia: tratar-se-ia de pensadores de vida contemplativa que, tratando donegotium, o estariam subordinando ao otium.

Mas, para discordar de Arendt, lembremos uma carta, que muitos dos que leram Maquiavel conhecem, na qual ele escreve a Francesco Vettori, a 10 de dezembro de 1513, para dizer-lhe que está redigindo um livrinho sobre os principados, que viria a chamar-se $O$ príncipe. Nessa carta, que data de poucos meses após a queda do regime ao qual Maquiavel serviu em Florença, queda esta que acarretou para ele próprio a prisão e a tortura, é fascinante ver como nosso autor conta passar o dia e a noite. De dia, trabalha nos campos; de noite, voltando à casa, limpa-se, veste as melhores roupas, e entra em contato com os antigos. Lê-os e escreve sobre o poder. Eis um exemplo magnífico do que são o otium e a vida contemplativa, mas, no caso, justamente para mostrar um certo equívoco de Arendt. Afirma ela que a Filosofia essencializa a política, e que a Filosofia Política, buscando, na política, a verdade sob a espécie da eternidade, perde de vista o seu cerne, que é o lado perturbado, em constante mutação, das coisas do poder. Mas com isso é ela quem esquece que boa parte da Filosofia Políticanão é a Filosofia aplicada à política: basta ver como, nesse caso de Maquiavel, se misturam o ócio e o negócio. Se nesse tempo o secretário florentino não está imerso no negotium é porque foi impedido, mas continua a ser esse o assunto que lhe interessa. Disso resulta um dos livros mais seguramente preocupados com essa espuma da vida política, com isso que, diz Arendt, é o não-estudado da Filosofia Política. Temos aí uma obra que não procura reduzir a vida política a um ou dois princípios dos quais tudo se deriva. Maquiavel não é Platão. A crítica que Arendt faz à política de Platão é pertinente, mas não a Maquiavel.

A razão mesma para vermos uma diferença decisiva entre a Filosofia e a Filosofia Política é, justamente, que o texto de 
Filosofia Política pede a seu leitor que o torne efetivo. Podemos conceber de várias maneiras a leitura de um texto. A leitura de um texto de Filosofia Política passa, essencialmente, pela demanda que o autor faz a seu leitor para que incorpore esse trabalho e o torne válido.

É o que, por exemplo, afirma Thomas Hobbes na introdução à sua obra mais conhecida, o Leviatã: "depois de eu ter exposto claramente e de maneira ordenada minha própria leitura [do homem e da política], o trabalho que a outros caberá será apenas verificar se não encontram o mesmo em si próprios. Pois esta espécie de doutrina não admite outra demonstração"..1 Trata-se, pois, de um livro escrito essencialmente para o leitor (argumentei, em outro lugar, que o destinatário por excelência da obra política hobbesiana é um leitor que se pauta pela justa avaliação de si mesmo, e não pelo medo²), a quem não se pede pouca coisa: quer-se que ele dê realidade ao livro, converta-o em prática.

Vejamos agora as linhas com que Hobbes conclui a Parte II dessa obra, que tem quatro partes, citando, pois, o que está exatamente em seu meio; ou, se considerarmos o Leviatã essencialmente como uma obra política e desconsiderarmos as duas partes finais, em que se trata de teologia política, como a conclusão dessa parte mais propriamente leiga. Nesse ponto estratégico, o filósofo expressa "a esperança de que esta minha obra venha um dia a cair nas mãos de um soberano, que a examinará por si próprio (pois é curta e penso que clara), sem a ajuda de algum intérprete interessado ou invejoso, e que pelo exercício da plena soberania, protegendo o ensino público desta obra, transformará esta verdade especulativa na utilidade da prática",, isto é, converterá o fruto do otiumem negotium. Não permite esta passagem ver que Arendt engessou os termos de uma oposição heurística? A Filosofia Política não é mera vida contemplativa! Mesmo um autor como Rousseau, que no fim da vida escreve mais essa obra-prima que são Os devaneios do caminhante solitário, de profunda tristeza e grandeza d'alma, nas obras propriamente políticas, se empenha em tornar carne o seu verbo. O campo de leitura na Filosofia Política é, pois, o campo de efetivação de sua escrita.
Evidentemente, isso traz outra questão, que será minha última: que relação tem isso com a Ciência Política? Cabe começar lembrando que, de modo geral, os filósofos políticos se disseram cientistas políticos. Nós os chamamos de filósofos políticos, mas Hobbes, por exemplo, diz que a Ciência Política "não é mais velha que meu livro Do Cidadão". Ou, antes dele, Maquiavel — no capítulo XV de $O$ príncipe - afirma que tudo o que até então se disse dos Estados tratou de quimeras, e quem se pautasse pelas teorias políticas precedentes aprenderia melhor a própria ruína do que o modo de manter seu Estado, e por isso é que nosso autor se propõe a escrever "coisa útil e verdadeira": com isso ele pretende também ser o fundador da Ciência Política. A questão portanto é: o que faz esses autores, que se definiam como cientistas, serem considerados por nós filósofos políticos? Isso, aliás, sem desacordo entre as disciplinas, porque a disposição da Filosofia Política a aceitá-los em seu campo se casa muito bem com a disposição dos cientistas políticos a ejetá-los de seu próprio.

E assim, numa trilha mais ou menos sinuosa, ora afirmo que a Filosofia Política é Filosofia — na medida em que tem, com sua história, a relação enriquecedora do presente permanente que caracteriza os clássicos - ora que não o é, na medida em que sua relação com o leitor é de outra ordem, pertencendo a um campo que é mais da ação que do conhecimento. Disso, porém, se entende a situação sempre ambígua, necessariamente ambígua, de uma disciplina que talvez se distinga justamente porque os seus cientistas políticos, ao passarem para o passado, mudam de profissão, tornando-se filósofos políticos - como se a ciência fosse da ordem da eficácia no presente e a Filosofia do plano do clássico e do patrimônio, como se uma mais ou menos se apagasse diante de seu objeto e a outra se avultasse ao tecer uma história construída, antes de mais nada, do acesso impossível à coisa mesma, do acesso barrado a esse objeto que se mostra fugidio. Talvez isso nos permita, aliás, um rápido balanço recíproco dos defeitos quer da Filosofia, quer da Ciência, Políticas.

Até por precaução, começo falando mal de minha disciplina. Embora Arendt se possa ter enganado ao perder 
de vista o caráter rico, e não estático, da oposição entre otium e negotium, o fato é que no ambiente filosófico a política acaba sendo uma espécie de prima pobre - papel, aliás, que ela reparte com a ética: academicamente, aquilo que lida com a ação fica num segundo plano em face do que trata do ser e de seu conhecimento.

E isto apesar de boa parte da melhor produção filosófica de nosso século e do anterior debater a ação e seus problemas, próximos ou indiretos: o homem como existência, como vazio, como ser-para-a-morte - em todos esses casos a ação, ou a inação, está em cena. Mas, da pouca atenção atribuída na academia a esses temas ressalta uma dificuldade de duplo perfil: primeiro, a de pensar o mundo presente e suas transformações - o que talvez responda pela freqüente overdose de melancolia que comparece nas análises filosóficas do tempo atual segundo, o descompasso que se estabelece entre o que é pensamento fremente e o que é estudo universitário do mesmo pensamento. Pergunto-me se de fato a universitarização, por assim dizer, da Filosofia será benéfica. Ela terá perdido, pelo menos, o seu gume. A Filosofia Política terá perdido, por vezes, o vínculo com aquele verbo grego prattein, que designa a ação de sujeitos sobre sujeitos ou com sujeitos, e que caracteriza uma ação humana distinta daquela que incide sobre objetos, ferramentas ou a matéria bruta: ao verbo prattein corresponde o substantivo praxis, que contrasta assim com outro tipo de ação que é a fabricação, na qual o homem lida com objetos e não com seus semelhantes. É bom lembrar, com Arendt e outros, que um dos grandes problemas de nosso tempo é a degradação da praxis em fabricação; mas, antes de insistir nisso, notemos que a Filosofia Política, ela mesma, com freqüência tem descuidado desse aspecto essencial entre os humanos que é o da açãopolítica.

Mas, se este é o problema de minha disciplina, permito-me agora tecer um ou dois comentários sobre a Ciência Política e, talvez, sobre as ciências sociais que, porém, expressos que são por alguém alheio ao campo, podem ser equivocados - e por isso desde logo me desculpo.
O primeiro problema é o de como lidar com a ação. Com demasiada freqüência se tem reduzido a ação inter-humana a coisa. Desde uma frase de Durkheim sobre os fatos sociais — instando-nos a considerá-los como coisas —, que é inteiramente correta se o que se quer é retirar um véu espiritualizante a dificultar o desenvolvimento de uma ou mais ciências do homem e da sociedade, tende-se, porém, em excesso a esquecer esses traços decisivos da ação propriamente humana, com os quais as ciências do homem têm de lidar. Resumi-los-ia em dois. Primeiro, tratando-se do homem, nunca temos um objeto em estado puro. $\mathrm{O}$ objeto também é sujeito, e isso vale tanto para a Psicologia quanto para as ciências do coletivo. Segundo, as significações dos atos - aquilo que uma ciência que não fosse humana deveria ignorar ou mesmo desprezar, no sentido forte do verbo, como constituindo erro — são relevantes. O que, aliás, exige lembrar que o estatuto do erro nas ciências humanas, como o da história da Filosofia na Filosofia, é relevante. Não se deleta, tratando-se do ser humano, o erro: ele exige ser conhecido. Por vezes, com o nome de ato falho, pode ser extremamente precioso. Em suma, no propósito de conhecer o(s) homem(ns), o último estado do conhecimento obtido não apaga os anteriores; o acerto, se é que existe, não exclui os erros, e isso pelas duas razões antes expostas: primeira, a perturbação introduzida por coincidirem o sujeito cognoscente e seu objeto, e a segunda, a relevância das significações, ainda que equivocadas, presentes nas ações humanas.

A questão que cabe, assim, para as ciências sociais é se não têm elas, eventualmente, e com a exceção da Antropologia, tratado as ações entre os homens como dependendo menos do prattein que da fabricação, esquivando assim o problema do sujeito nas ciências humanas — que não é apenas um óbice a ser vencido, mas constitui um dado constitutivo do corpus e da relação de conhecimento por ele admitida — e o das significações.

Um segundo problema diz respeito ao papel da teoria nas ciências sociais em geral. Tem havido em nosso país, desde um certo tempo, grande preocupação com os métodos, com a teoria de referência - e penso, sobretudo, não nas teorias clássicas mas nos comentadores mais recentes, mais 
atuais, como, há uns 20 anos atrás, Gramsci, depois a escola de Frankfurt, e sempre outros novos. Houve um esforço muito grande das agências de fomento e sobretudo dos programas de pós-graduação no sentido de aprimorar a discussão acadêmica e, no caso, o embasamento teórico das pesquisas. Contudo, dois pontos devem ser salientados. Primeiro, com excessiva freqüência o comentador da moda era apenas um intermediário entre uma teoria mais forte e o seu leitor. Assim, Gramsci e mesmo Marta Hanecker serviram de porta para o conhecimento de Marx que, ele próprio, parecia não estar ao alcance de seu leitor. Tenho para mim, mas isso desenvolverei outra hora, que assim se repetia, na leitura dita acadêmica, velho dispositivo característico do acesso católico aos textos sagrados, e antes de mais nada às Escrituras, pelo qual elas só podiam ser compreendidas mediante um intermediário e por vezes um intercessor, fosse ele um profeta, fosse ele uma Igreja. Daí que a leitura direta dos textos fosse rara, e em seu lugar se priorizasse esse trabalho de menor alcance, o da legitimação da própria leitura através de outra, antes realizada, que diluiria e tornaria prática a escrita do autor de referência.

Segundo, como esses referentes legitimadores se substituem com boa velocidade, sua aplicação ao corpus ou ao objeto tratado se dava e se dá com um automatismo nocivo. Não se procura ver qual a teoria, ou o instrumental teórico, adequado para tal ou qual tema; mais que isso, cada orientador ou grupo de pesquisa, esposando uma doutrina, faz com que ela se aplique indistintamente a todo objeto que lhe seja proposto. Com isso, a teoria se torna mais, ou outra coisa, do que ela é. Porque uma teoria, como aliás diz Foucault a respeito de Nietzsche tal como ele o utilizou, não passa de uma caixa de ferramentas, que serve para dar a conhecer. Se ela, ao invés disso, é tratada, primeiro, pelo registro da revelação mediada por profetas ou pelo clero, segundo, por sua aplicação indistinta a qualquer objeto, o que temos não é teoria, mas religião; e esta tem seu valor, sua importância, mas não para proporcionar um conhecimento científico.

Que balanço final propor? Tem faltado à Filosofia Política tratar da ação: isso a leva à cilada da melancolia, à dificuldade de lidar com o que sucede, à tentação — mais de um tipo de Filosofia que da própria Filosofia Política a converter-se em refúgio ante tempos adversos (o que é particularmente visível naqueles que, depois da queda do Muro, se tornaram o que Ernildo Stein muito apropriadamente chamou "órfãos da utopia"). Já à Ciência Política tem faltado considerar o que é próprio na ação humana, aquilo em que ela se distingue da simples fabricação. E ganhariam, as ciências sociais, em ter mais teoria, ou em tê-la de outro modo: porque ela com freqüência se aplica mecanicamente, ou se canoniza. A nós todos o que assim falta é maior conhecimento uns dos outros, maior freqüentação recíproca, que poderá dar cabo dessas falhas que se prolongam por maior tempo do que deveriam.

\section{NOTAS}

1 Leviatã, tradução de João Paulo Monteiro e Maria Beatriz N. da Silva, São Paulo, Abril, 1974, p. 10; orig.Leviathan, Penguin, 1968.

2 Ao leitor sem medo, São Paulo, Brasiliense, 1984.

3 Leviatã, op.cit., cap. XXXII, p. 222. 